This is a self-archived - parallel published version of this article in the publication archive of the University of Vaasa. It might differ from the original.

\title{
Zero Energy Building by Multi-Carrier Energy Systems including Hydro, Wind, Solar and Hydrogen
}

Author(s): Mehrjerdi, Hasan; Hemmati, Reza; Shafie-khah, Miadreza; Catalao, Joao P.S.

Title: $\quad$ Zero Energy Building by Multi-Carrier Energy Systems including Hydro, Wind, Solar and Hydrogen

Year: $\quad 2020$

Version: Accepted manuscript

Copyright (C) 2020 IEEE. Personal use of this material is permitted. Permission from IEEE must be obtained for all other uses, in any current or future media, including reprinting/republishing this material for advertising or promotional purposes, creating new collective works, for resale or redistribution to servers or lists, or reuse of any copyrighted component of this work in other works.

Please cite the original version:

Mehrjerdi, H., Hemmati, R., Shafie-khah, M. \& Catalao, J. P. S. (2020). Zero Energy Building by Multi-Carrier Energy Systems including Hydro, Wind, Solar and Hydrogen. IEEE Transactions on Industrial Informatics (Vol. ahead-of-print No. ahead-of-print). https://doi.org/10.1109/TII.2020.3034346 


\title{
Zero Energy Building by Multi-Carrier Energy Systems including Hydro, Wind, Solar and Hydrogen
}

\author{
Hasan Mehrjerdi, Senior Member, IEEE, Reza Hemmati, Miadreza Shafie-khah, Senior Member, IEEE, \\ and João P. S. Catalão, Senior Member, IEEE
}

\begin{abstract}
This paper proposes a unified solution to address the energy issues in net zero energy building (ZEB), as a new contribution to earlier studies. The multi-carrier energy system including hydro-wind-solar-hydrogen-methane-carbon dioxidethermal energies is integrated and modeled in ZEB. The electrical sector is supplied by hydro-wind-solar, combined heat and power (CHP), and pumped hydro storage (PHS). The thermal sector is supplied by CHP, thermal boiler and electric heating. The hydrogen storage system and Methanation process operate as the interface energy carriers between the electrical and thermal sectors. The carbon dioxide $\left(\mathrm{CO}_{2}\right)$ of the $\mathrm{ZEB}$ is captured and fed into the Methanation process. The purpose is minimizing the released $\mathrm{CO}_{2}$ to the atmosphere while all the electrical-thermal load demands are successfully supplied considering events and disruptions. The model improves simultaneously the energy resilience and minimizes the environmental pollutions. The results demonstrate that the developed model reduces the $\mathrm{CO}_{2}$ pollution by about $33451 \mathrm{~kg}$ per year. The model is a resilient energy system that can handle all failures of components. The model can efficiently handle $26 \%$ increment in the electrical loads and $110 \%$ increment in the thermal loads.
\end{abstract}

Index Terms - Carbon Dioxide, Multi-Carrier Energy System, Net Zero Energy Building, Renewable to Gas, Thermal Load.

\section{NOMENCLATURE}

\begin{tabular}{|c|c|}
\hline \multicolumn{2}{|l|}{ Sets and indexes } \\
\hline th & Index of hours \\
\hline$t s$ & Index of seasons \\
\hline$T 1$ & Set of seasons \\
\hline$T 2$ & Set of hours \\
\hline \multicolumn{2}{|l|}{ Parameters } \\
\hline$C_{c o}$ & Factor to convert $\mathrm{CO}_{2}$ to methane \\
\hline$C_{h y}$ & Factor to convert hydrogen to methane \\
\hline$C_{m t e}$ & Factor to convert methane to electricity \\
\hline$C_{p t h}$ & Factor to convert electricity to hydrogen \\
\hline$E_{p h s}^{n}$ & Capacity of pumped hydro storage $(\mathrm{kWh})$ \\
\hline$E_{p h s}^{i n i}$ & Initial energy of pumped hydro storage $(\mathrm{kWh})$ \\
\hline$P_{a}, P_{b}, P_{c}, P_{d}$ & $\begin{array}{l}\text { Boundaries of produced electrical energy by combined } \\
\text { heat and power }\end{array}$ \\
\hline$P_{\text {wind }}^{\text {ts, th }}$ & Wind power $(\mathrm{kW})$ \\
\hline$P_{p v}^{t s, t h}$ & Solar power $(\mathrm{kW})$ \\
\hline$P_{h y}^{t s, t h}$ & Micro hydro turbine power $(\mathrm{kW})$ \\
\hline$P_{\text {load }}^{t s, t h}$ & Load power $(\mathrm{kW})$ \\
\hline$P_{p h s}^{n}$ & Nominal power of pumped hydro storage $(\mathrm{kW})$ \\
\hline$S_{h}^{i n i}$ & Initial hydrogen inside hydrogen tank $(\mathrm{kg})$ \\
\hline$S_{h}^{n}$ & Capacity of hydrogen tank (kg) \\
\hline$S T^{t s}$ & Set of days in each season \\
\hline
\end{tabular}

\begin{tabular}{|c|c|}
\hline$T_{a}, T_{b}, T_{c}, T_{d}$ & $\begin{array}{l}\text { Boundaries of produced thermal energy by combined } \\
\text { heat and power }\end{array}$ \\
\hline$T_{\text {load }}^{\text {ts,th }}$ & Thermal load $(\mathrm{kW})$ \\
\hline$T_{t b}^{n}$ & Capacity of thermal boiler $(\mathrm{kW})$ \\
\hline$\eta_{c h p}^{t}$ & Thermal efficiency of combined heat and power (\%) \\
\hline$\eta_{t b}^{t}$ & Efficiency of thermal boiler (\%) \\
\hline$\eta_{h s}^{t s}$ & Efficiency of hydrogen storage unit (\%) \\
\hline$\eta_{e h}^{t}$ & Efficiency of electric heating (\%) \\
\hline$\eta_{c h p}^{e}$ & Electrical efficiency of combined heat and power (\%) \\
\hline$T_{e h}^{n}$ & Capacity of electric heating $(\mathrm{kW})$ \\
\hline$\eta_{p h s}^{t s}$ & Efficiency of pumped hydro storage (\%) \\
\hline$\eta_{w e}$ & Efficiency of water electrolyzer (\%) \\
\hline \multicolumn{2}{|l|}{ Variables } \\
\hline$C \mathrm{O}_{2}^{t s, t h}$ & Released carbon dioxide to air $(\mathrm{kg})$ \\
\hline$E p$ & Ambient carbon dioxide $(\mathrm{kg})$ \\
\hline$E_{p h s}^{t s, t h}$ & Energy of pumped hydro storage $(\mathrm{kWh})$ \\
\hline$E C^{t s, t h}$ & Electricity consumption $(\mathrm{kW})$ \\
\hline$E G^{t s, t h}$ & Electricity generation $(\mathrm{kW})$ \\
\hline$H_{m e}^{t s, t h}$ & Consumed hydrogen by methanation process $(\mathrm{kg})$ \\
\hline$H_{w e}^{t s, t h}$ & Produced hydrogen by water electrolyzer $(\mathrm{kg})$ \\
\hline$M_{t}^{t s, t h}$ & Produced methane $(\mathrm{kg})$ \\
\hline$M_{c h p}^{t s, t h}$ & Consumed methane by combined heat and power $(\mathrm{kg})$ \\
\hline$M_{t b}^{t s, t h}$ & Consumed methane by thermal boiler $(\mathrm{kg})$ \\
\hline$P_{d p h s}^{t s, t h}$ & Discharged power from pumped hydro storage $(\mathrm{kW})$ \\
\hline$P_{c h p}^{t s, t h}$ & Power of combined heat and power $(\mathrm{kW})$ \\
\hline$P_{w e}^{t s, t h}$ & Water electrolyzer power $(\mathrm{kW})$ \\
\hline$P_{e h}^{t s, t h}$ & Electric heating power $(\mathrm{kW})$ \\
\hline$P_{c p h s}^{t s, t h}$ & Charged power to pumped hydro storage $(\mathrm{kW})$ \\
\hline$T G^{t s, t h}$ & Thermal generation $(\mathrm{kW})$ \\
\hline$T_{c h p}^{t s, t h}$ & Thermal energy of combined heat and power $(\mathrm{kW})$ \\
\hline$T_{e h}^{t s, t h}$ & Thermal energy of electric heating $(\mathrm{kW})$ \\
\hline$T_{t b}^{t s, t h}$ & Thermal energy of thermal boiler $(\mathrm{kW})$ \\
\hline$T C^{t s, t h}$ & Thermal consumption $(\mathrm{kW})$ \\
\hline$u_{p h s}^{t s, t h}$ & Binary variable of pumped hydro storage \\
\hline$u_{p h s}^{t s, t h}$ & Binary variable of pumped hydro storage \\
\hline$S_{h}^{t s, t h}$ & Stored hydrogen $(\mathrm{kg})$ \\
\hline
\end{tabular}




\section{INTRODUCTION}

\section{A. Motivation and incitement}

The energy management in the buildings connected to the external grid is usually addressed through home energy management system (HEMS). The ZEB is a form of system in which the building is not connected to the upstream grid. The ZEB is an efficient solution to address the energy issues in the buildings such as costs and pollutions. The ZEB could even be feasible with electricity production when enough renewable energies are integrated. Various sorts of renewable and nonrenewable resources, energy storages and the other capacity resources have been successfully utilized in ZEBs. The energy resilience in $\mathrm{ZEB}$ is not sufficient because the building is not connected to the utility grid. One of the effective solutions to address such problem is to utilize multi-carrier energy hub in the ZEBs. The multi-carrier energy systems and energy hubs have been widely modeled and studied to cope with energy issues. However, application of a comprehensive model that could handle all issues at the same time has not been reported. The reported models usually consider multiple resources but some aspects of the problem are not included and investigated. While all aspects of such plan make impact on each other and it is compulsory to model and evaluate all aspects together in order to discover how they make mutual effects on each other. In this regard, a comprehensive model is addressed by this paper including multiple energy resources (i.e., hydro, gas, sun, wind, Methane, and hydrogen), multiple energy devices (i.e., energy storage, power-to-gas process, CHP, boiler), environmental issues, and technical-economic aspects.

\section{B. Literature review}

The net zero energy building (ZEB) is an integrated solution to handle the energy issues such as pollutions and energy-saving in the buildings. In terms of renewable resources, different renewable types have been broadly applied for potential integration in ZEB. The life cycle assessment is a useful indicator to evaluate the performance of ZEB [1]. The zero energy buildings are assessed based on the life cycle and some indicators like net energy ratio (NER) have been developed to design a building subject to life cycle [2]. The feasibility of ZEB depends on the energy resources and the economic issues are the primary concerns for developing such buildings. The studies indicate that life cycle cost is related to the district where the $\mathrm{ZEB}$ is constructed and it is not economic to in some regions. For instance, if the building is supplied by solar photovoltaic energy, life cycle cost would not be economic in the cold areas. However, such issues may be fixed with providing financial subside by the government for PV integration [3].

The home energy management [4] and The ZEBs have been developed to reduce the negative effects of the buildings on the environment as well as minimization of energy consumptions in the building sector [5]. Such buildings are not connected to the electrical grid and their energy is supplied by their own resources. The combined effects of the renewables and storages like PV, wind, and batteries are applicable for such buildings [6]. A variety of energy storage technologies like hydrogen storage [7], hydro storage, battery [8], thermal energy [9], hybrid energy storage [10] are relevant for such buildings. The ZEBs make significant impacts on $\mathrm{CO}_{2}$ reduction [11].
The renewable and non-renewable energies are widely integrated with ZEBs. The hydro, wind [12], solar [13], combined heat and power (CHP) [14], fuel cell [15], and diesel generator [16] may be usefully installed in ZEBs.

The resilience of ZEB may be improved by utilizing multicarrier energy hub [17] rather than single carrier energy system based on electricity [18]. The multi-carrier energy systems include electricity, thermal energy, water, hydrogen, and cold energies $[19,20]$. The input energies to the system are regularly electricity, gas, and water and the output loads are normally the electrical load, thermal and cold loads [21]. The electrical energy may be harvested from renewables, non-renewables, or electrical grid [22]. The input gas is taken from the natural gas pipeline too [23]. The multi-carrier energy systems use different interface devices to convert energy from one form to another form where the electrical energy, hydrogen, thermal energy, cold energy and natural gas are properly converted to each other [24]. Such transformations allow the multi-carrier energy hub to supply different load types efficiently. The multi-energy systems are useful to reduce environmental pollutions [25].

\section{Contributions and paper organization}

As it was stated, the ZEB has insufficient energy resilience because of off-grid operation. This issue may be addressed by utilizing multi-carrier energy systems. Many configurations of multi-carrier energy systems have been utilized in ZEBs. However, a comprehensive model including all feasible resources and capacities at the same time has not been addressed so far. It is required to study the mutual effects of multiple resources on each other in order to improve the technical (e.g., resilience) and economic (e.g., costs) parameters. The current paper presents a unified solution to address most of the energy issues in ZEB, as a new contribution to earlier studies. Multicarrier energy system including water, natural gas, sun, wind, Methane, and hydrogen is utilized to supply the electrical and thermal loads. The main highlights of the model are addressed as below:

- $\quad$ The ZEB is supplied through multi-carrier energy hub.

- The developed multi-carrier energy hub is practical for all climate regions because it utilizes different energy carriers that are available in various regions.

- In order to improve the energy resilience, the electrical and thermal loads are supplied through parallel paths.

- The electrical section is fed by hydro, solar, wind, CHP, and PHS systems.

- The thermal section is fed by CHP, thermal boiler, and electric heating.

- The hydrogen and Methane are the medium carriers between electric and thermal sections.

- The $\mathrm{CO}_{2}$ released by the building is captured and combined into hydrogen to produce Methane.

- The model minimizes the released $\mathrm{CO}_{2}$ into air and improves system resilience.

- It supplies the electrical-thermal loads with minimum load shedding under failures of components.

The paper organization is as follows: Section II describes the proposed multi-carrier energy system, Section III presents the operation and modeling of integrated energy systems, Section IV introduces the test system, and Section $\mathrm{V}$ shows the numerical results and discussions. The conclusions are summarized in Section VI. 


\section{PROJECTED MULTI-CARRIER ENERGY SYSTEM}

Fig. 1 represents the general view of the projected multicarrier energy system to supply net zero energy building (ZEB) and Fig. 2 shows the details of the model. As shown by Fig. 1, the multi-energy carrier system is used to supply the electrical and thermal loads in ZEB.

The electrical energy is harvested from renewable energies including hydro-wind-solar and combined heat and power (CHP). The pumped hydro storage (PHS) is included to level the intermittency of the renewable energies.

The detail of the proposed multi-carrier energy system is depicted in Fig. 2. The electricity is the base energy carrier of the system. In order to increase the availability of the electrical energy, different energy resources including wind, solar, hydro and CHP are utilized. The PHS is equipped to level the intermittency of input energies. The electric heating is also fed by electrical energy. The excess of electricity is converted to hydrogen and stored in the hydrogen reservoir. The hydrogen is then converted to Methane in order to supply the CHP and thermal boiler. The Methanation process not only produces the natural gas for thermal units but also consumes $\mathrm{CO} 2$ and reduces the pollutions. In the thermal section, the thermal load is supplied by thermal boiler, CHP and electric heating. The CHP also produces the electricity to supply the electrical load demand. There are six energy carriers in the system including electricity, hydrogen, Methane, Thermal energy, CO2, and micro hydro turbine power. The developed model uses different electrical and thermal resources in parallel to supply the loads. The system resilience is improved by such model. Because the system is able to continue load service when one of the energycarriers or components is not functioning. The resilience is important in the ZEB because the system is not connected to the electrical grid and the installed resources in the building are responsible to supply the load demand under all events and failures.

The defined test system may be a small village, hospital, university campus, large farm, or a residential complex which is not connected to the upstream grid and needs off-grid energy management. The disconnection from the utility grid may even be temporary. It means that the test system does not necessarily need to be far from the electrical grid, but because of some economic or technical limitations has to (or prefer to) operate as standalone. Nevertheless, the proposed model may be used and run for building energy management at any region based on the local data. As well, the toolbox has enough flexibility to be used when some components are not present.

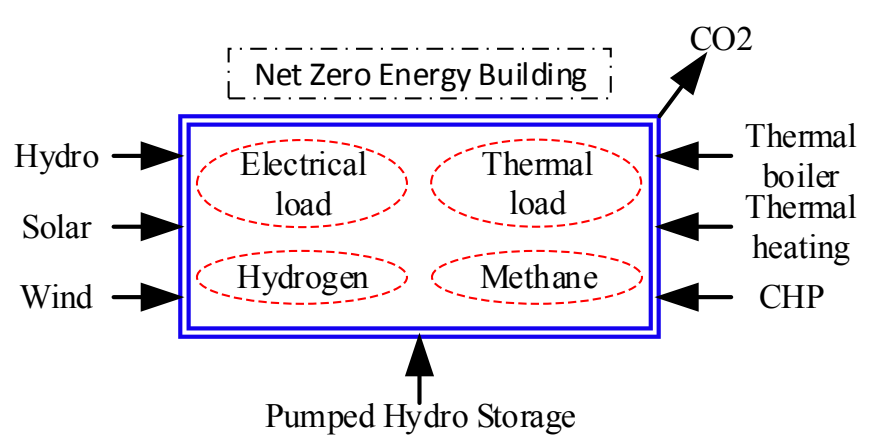

Fig. 1: Multi-carrier energy system in net zero energy building.

\section{FEASIBLE OPERATION OF ENERGY SYSTEMS}

\section{A. Feasible operation region of $\mathrm{CHP}$}

Fig. 3 shows the typical feasible operation region of CHP where the boundaries are modeled by points $a, b, c$, and $d$. The operation either must be inside the region or the CHP must be shutdown $[26,27]$. The line between points $a-b$ is modeled by (1). The line from point $b$ to point $c$ is modeled by (2) and the line between points $\mathrm{c}-\mathrm{d}$ is modeled by (3). The last line from point $\mathrm{d}$ to point a is given by (4) [28].

$$
\begin{aligned}
& P_{c h p}^{t s, t h} \leq\left\{\begin{array}{c}
P_{a} \times u_{p h s}^{t s, t h}+\left(\left(P_{b}-P_{a}\right) /\left(T_{b}-T_{a}\right)\right) \\
\times\left(T_{c h p}^{t s, t h}-T_{a} \times u_{p h s}^{t s, t h}\right)
\end{array}\right\} \forall t s \in T 1, t h \in T 2 \\
& P_{c h p}^{t s, t h} \geq\left\{\begin{array}{c}
P_{b} \times u_{p h s}^{t s, t h}+\left(\left(P_{c}-P_{b}\right) /\left(T_{c}-T_{b}\right)\right) \\
\times\left(T_{c h p}^{t s, t h}-T_{b} \times u_{p h s}^{t s, t h}\right)
\end{array}\right\} \forall t s \in T 1, t h \in T 2 \\
& P_{c h p}^{t s, t h} \geq\left\{\begin{array}{c}
P_{c} \times u_{p h s}^{t s, t h}+\left(\left(P_{d}-P_{c}\right) /\left(T_{d}-T_{c}\right)\right) \\
\times\left(T_{c h p}^{t s, t h}-T_{c} \times u_{p h s}^{t s, t h}\right)
\end{array}\right\} \quad \forall t s \in T 1, t h \in T 2 \\
& T_{c h p}^{t s, t h} \geq 0 \\
& \forall t s \in T 1, t h \in T 2
\end{aligned}
$$

If the produced electrical power is zero, the CHP therefore must be switched off as indicated by (5). As well, the CHP cannot produce thermal energy when the electrical energy is zero as modeled by (6). The relationship between input fuel to CHP and output electrical-thermal energies is given by (7) [26].

$$
\begin{array}{ll}
\text { if }\left\{P_{c h p}^{t s, t h}\right\}=0 \Rightarrow\left\{u_{p h s}^{t s, t h}\right\}=0 & \forall t s \in T 1, t h \in T 2 \\
\text { if }\left\{P_{c h p}^{t s, t h}\right\}=0 \Rightarrow\left\{T_{c h p}^{t s, t h}\right\}=0 & \forall t s \in T 1, t h \in T 2 \\
\left\{\begin{array}{c}
\eta_{c h p}^{e} \times P_{c h p}^{t s, t h}+\eta_{c h p}^{t} \\
\times T_{c h p}^{t s, t h}
\end{array}\right\}=\left\{M_{c h p}^{t s, t h} \times C_{m t e}\right\} & \forall t s \in T 1, t h \in T 2
\end{array}
$$

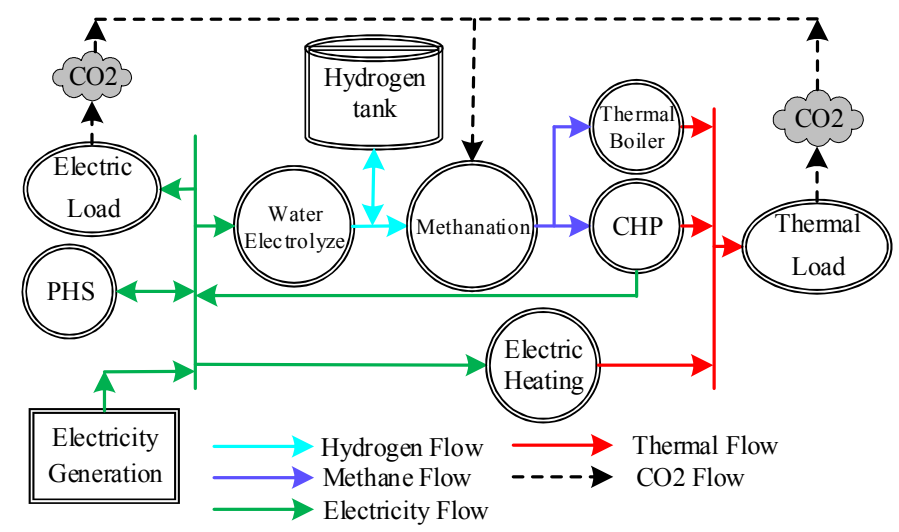

Fig. 2: Details of the developed multi-carrier energy system.

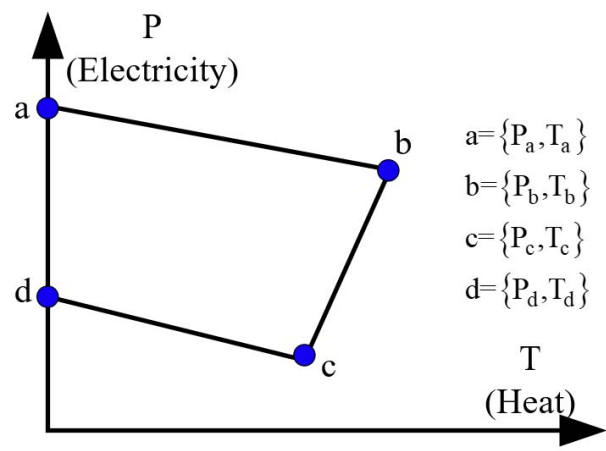

Fig. 3: Feasible operation region of CHP. 


\section{B. Feasible operation of PHS}

The PHS operates like usual energy storage systems. The charged power to the PHS is given by (8) and the discharged power is modeled by (9). The model only actives one of the charged-discharged powers at each time interval [[29].

$$
\begin{array}{ll}
P_{c p h s}^{t s, t h} \leq\left\{P_{p h s}^{n} \times u_{p h s}^{t s, t h}\right\} & \forall t s \in T 1, t h \in T 2 \\
P_{d p h s}^{t s, t h} \leq\left\{P_{p h s}^{n} \times\left(1-u_{p h s}^{t s, t h}\right)\right\} & \forall t s \in T 1, t h \in T 2
\end{array}
$$

The hydro energy is stored in the PHS system as modeled by (10). The initial energy inside the upper reservoir may also be included as demonstrated by (11). The upper reservoir capacity is limited by (12) and the whole efficiency of the PHS is addressed by (13) [29].

$$
\begin{array}{rr}
E_{p h s}^{t s, t h}=\left\{E_{p h s}^{t s, t h-1}+\left[P_{c p h s}^{t s, t h}-P_{d p h s}^{t s, t h}\right]\right\} & \forall t s \in T 1, t h \in T 2 \\
E_{p h s}^{t s, t h-1}=E_{p h s}^{i n i} & \forall t s \in T 1, t h=1 \\
E_{p h s}^{t s, t h} \leq E_{p h s}^{n} & \forall t s \in T 1, t h \in T 2 \\
\eta_{p h s}^{t s}=\left\{\sum_{t h=1}^{T 2} P_{d p h s}^{t s, t h} / \sum_{t h=1}^{T 2} P_{c p h s}^{t s, t h}\right\} & \forall t s \in T 1
\end{array}
$$

The given model is a general model for energy storage systems. The PHS system may be substituted with the other energy storage systems like battery. The only difference is about the investment and operational costs. The battery comprises higher costs. The user only needs to change some input data like efficiency, rated power, and capacity according to the new energy storage type.

\section{Hydrogen production and methanation}

The water electrolyzer converts electricity to hydrogen as modeled in (14). The produced hydrogen is stored in hydrogen storage tank as given by (15). The initial hydrogen inside the hydrogen tank may also be included in the model as modeled in (16) [30].

$$
\begin{array}{ll}
H_{w e}^{t s, t h}=\left\{P_{w e}^{t s, t h} \times C_{p t h} \times \eta_{w e}\right\} & \forall t s \in T 1, t h \in T 2 \\
S_{h}^{t s, t h}=\left\{S_{h}^{t s, t h-1}+\left[H_{w e}^{t s, t h}-H_{m e}^{t s, t h}\right]\right\} & \forall t s \in T 1, t h \in T 2 \\
S_{h}^{t s, t h-1}=S_{h}^{i n i} & \forall t s \in T 1, t h=1
\end{array}
$$

The capacity of hydrogen tank is specified by (17) and efficiency of whole hydrogen storage system is denoted by (17). The hydrogen is combined with carbon dioxide to make methane and the associated relationship is addressed in (19). Eventually, the synthesized methane is used to supply the CHP and thermal boiler as detailed by (20) [30].

$$
\begin{array}{ll}
S_{h}^{t s, t h} \leq S_{h}^{n} & \forall t s \in T 1, t h \in T 2 \\
\eta_{h s}^{t s}=\left\{\sum_{t h=1}^{T 2} H_{m e}^{t s, t h} / \sum_{t h=1}^{T 2} H_{w e}^{t s, t h}\right\} & \forall t s \in T 1 \\
M_{t}^{t s, t h}=\left\{\begin{array}{c}
H_{m e}^{t s, t h} \times C_{h y}+C O_{2}^{t s, t h} \\
\times C_{c o}
\end{array}\right\} & \forall t s \in T 1, t h \in T 2 \\
M_{t}^{t s, t h}=\left\{M_{c h p}^{t s, t h}+M_{t b}^{t s, t h}\right\} & \forall t s \in T 1, t h \in T 2
\end{array}
$$

\section{Electrical energy equilibrium}

The generated electricity by all generating systems is modeled by (21). It includes wind, solar, hydro, PHS, and CHP powers. The consumed power by system is also modeled as (22) including water electrolyzer, load demand, electric heating, and PHS powers. The electrical energy equilibrium is passed by (23) where the generation is equal to the consumption [30].

$$
\begin{aligned}
E G^{t s, t h}=\left\{\begin{array}{c}
P_{w i n d}^{t s, t h}+P_{p v}^{t s, t h}+P_{h y}^{t s, t h} \\
+P_{d p h s}^{t s, t h}+P_{c h p}^{t s, t h}
\end{array}\right\} & \forall t s \in T 1, t h \in T 2 \\
E C^{t s, t h}=\left\{\begin{array}{c}
P_{w e}^{t s, t h}+P_{l o a d}^{t s, t h}+P_{e h}^{t s, t h} \\
+P_{c p h s}^{t s, t h}
\end{array}\right\} & \forall t s \in T 1, \text { theT2 } \\
E G^{t s, t h}=E C^{t s, t h} & \forall t s \in T 1, t h \in T 2
\end{aligned}
$$

In the model, the hydro power and PHS are selected because of their correlation. The hydro power is harvested by micro hydro turbine from a river which flows beside the test system. The PHS pumps water from the river to the upper reservoir and stores energy. Then the water is released back into the river (lower reservoir) through a turbine.

\section{E. Thermal energy equilibrium}

The thermal energy of the system is generated by CHP, electric heating, and thermal boiler as shown in (24) and the thermal energy is consumed by thermal load as addressed by (25). The thermal energy balance is approved by (26) [30].

$$
\begin{aligned}
& T G^{t s, t h}=\left\{T_{c h p}^{t s, t h}+T_{e h}^{t s, t h}+T_{t b}^{t s, t h}\right\} \quad \forall t s \in T 1, t h \in T 2 \\
& T C^{t s, t h}=T_{\text {load }}^{\text {ts }, \text { th }} \quad \forall t s \in T 1, \text { th } \in T 2 \\
& T G^{t s, t h}=T C^{t s, t h} \\
& \forall t s \in T 1, t h \in T 2
\end{aligned}
$$

The thermal boiler operation is modeled in (27) where the injected methane to the thermal boiler is used to produce thermal energy. The capacity of thermal boiler is limited by (28). The operation of thermal heating is also modeled in (29) and its capacity is defined by (30) [30].

$$
\begin{aligned}
& T_{t b}^{t s, t h}=\left\{M_{t b}^{t s, t h} \times C_{m t e} \times \eta_{t b}^{t}\right\} \quad \forall t s \in T 1, t h \in T 2 \\
& T_{t b}^{t s, t h} \leq T_{t b}^{n} \\
& \forall t s \in T 1, t h \in T 2 \\
& T_{e h}^{t s, t h}=\left\{P_{e h}^{t s, t h} \times \eta_{e h}^{t}\right\} \\
& \forall t s \in T 1, t h \in T 2 \\
& T_{e h}^{t s, t h} \leq T_{e h}^{n} \\
& \forall t s \in T 1, t h \in T 2
\end{aligned}
$$

\section{F. Objective of the plan}

The projected ZEB supplies all electrical and thermal loads by utilizing the multi-carrier energy system including hydro, wind, solar, hydrogen, methane, carbon dioxide, and thermal energies. The purpose of the given model is to minimize the released carbon dioxide $\left(\mathrm{CO}_{2}\right)$ to the environment by $\mathrm{ZEB}$. This objective is defined as (31) and it calculates the annual $\mathrm{CO}_{2}$ of ZEB.

$$
E p=\sum_{t s=1}^{T 1} \sum_{t h=1}^{T 2}\left(C O_{2}^{t s, t h} \times S T^{t s}\right)
$$

In the given optimization programming, the objective function is defined by (31) and the constraints are presented through (1) to (30). The standard optimization programming is formulated as follows;

$$
\text { Minimizing Equation (31) }
$$
Subject to

$$
\text { Equations (1) to (30) }
$$

This optimization programming is expressed as mixed integer linear programming and solved by GAMS software (CPLEX solver).

\section{THE PROPOSED ZEB}

The ZEB comprises several energy-carriers and the technical data of these energy systems are presented in Table I [15]. The nominal power, nominal capacity, and efficiency of the systems are presented [30]. The feasible operation region of CHP is modeled by the boundaries presented in Table II. 
The load and energy profiles are presented for each season. The seasonal electrical load demand, thermal load demand, solar power, and micro hydro turbine power are shown in Figs. 4 to 7 $[7,16]$. The wind power is assumed to be constant over all seasons as shown in Table III. The coefficients for converting the energy carriers to each other are listed in Table IV [30].

The proposed model is prepared as a toolbox in GAMS software to design off-grid building. There is not any limitation on the toolbox to design building and it can be used for any location based on the local data. In order to confirm the outputs, the problem is solved several times by GAMS software and the outputs are checked. As well, some input data are changed and the outputs are then analyzed and evaluated to be correct according to the alterations in the input data. Such controls confirm that the model and solution are correct.

TABLE I

THE TECHNICAL DATA OF ENERGY SYSTEMS

\begin{tabular}{lc}
\multicolumn{1}{c}{ Item } & Level \\
\hline Peak of electrical load demand $(\mathrm{kW})$ & 25 \\
Peak of thermal load demand $(\mathrm{kW})$ & 10 \\
Peak of wind power $(\mathrm{kW})$ & 10 \\
Peak of micro hydro turbine power $(\mathrm{kW})$ & 10 \\
Peak of solar power $(\mathrm{kW})$ & 10 \\
Nominal power of PHS $(\mathrm{kW})$ & 50 \\
Nominal capacity of PHS $(\mathrm{kWh})$ & 10 \\
Initial energy of PHS $(\mathrm{kWh})$ & 0 \\
Initial hydrogen inside tank $(\mathrm{kg})$ & 0 \\
Nominal capacity of thermal boiler $(\mathrm{kW})$ & 3 \\
Nominal capacity of electric heating $(\mathrm{kW})$ & 4 \\
Efficiency of PHS $(\%)$ & 100 \\
Efficiency of water electrolyzing $(\%)$ & 60 \\
Efficiency of hydrogen storage system $(\%)$ & 100 \\
Efficiency of thermal boiler $(\%)$ & 80 \\
Efficiency of electric heating $(\%)$ & 80 \\
Thermal efficiency of CHP $(\%)$ & 40 \\
Electrical efficiency of CHP $(\%)$ & 30 \\
\hline
\end{tabular}

TABLE II

THE DATA OF CHP OPERATION REGION

\begin{tabular}{ccc}
\hline & $\mathrm{P}$ & $\mathrm{T}$ \\
\hline Point a & 10 & 0 \\
Point b & 8 & 8 \\
Point c & 4 & 5 \\
Point d & 6 & 0 \\
\hline
\end{tabular}

TABLE III

WIND SYSTEM POWER FOR ALL FOUR SEASONS

\begin{tabular}{ccccccccccccc}
\hline Hour & 1 & 2 & 3 & 4 & 5 & 6 & 7 & 8 & 9 & 10 & 11 & 12 \\
\hline $\begin{array}{c}\text { Power } \\
(\%)\end{array}$ & 100 & 95 & 90 & 85 & 80 & 75 & 70 & 65 & 60 & 55 & 50 & 45 \\
\hline Hour & 13 & 14 & 15 & 16 & 17 & 18 & 19 & 20 & 21 & 22 & 23 & 24 \\
\hline $\begin{array}{c}\text { Power } \\
(\%)\end{array}$ & 40 & 35 & 30 & 25 & 25 & 35 & 45 & 55 & 65 & 75 & 85 & 95 \\
\hline
\end{tabular}

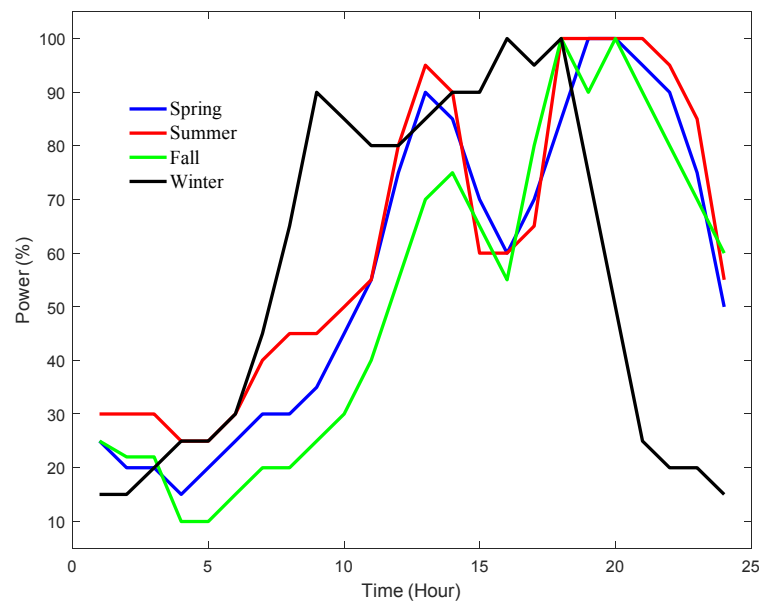

Fig. 4: Electrical load demand in each season.

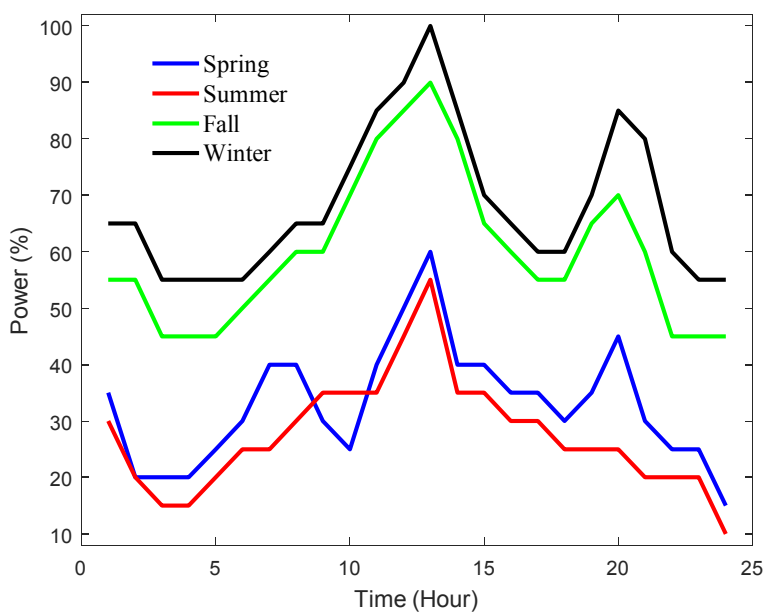

Fig. 5: Thermal load demand in each season.

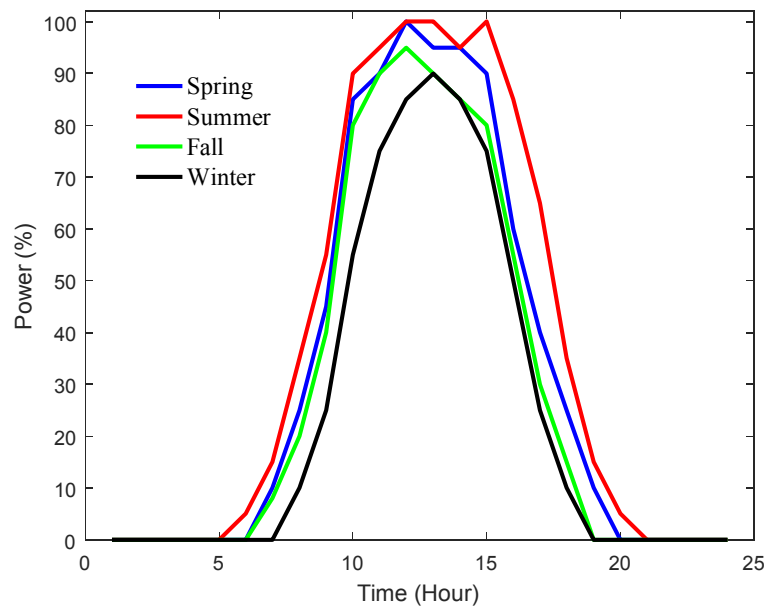

Fig. 6: Solar system power in each season.

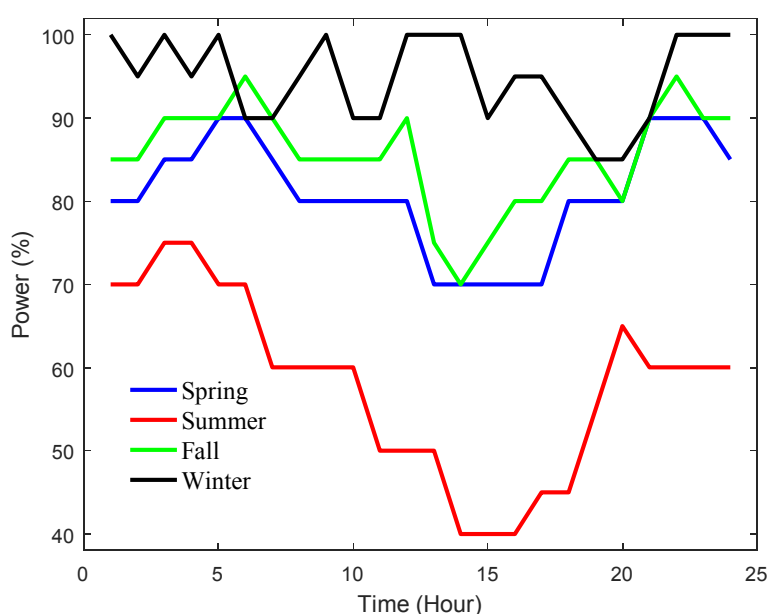

Fig. 7: Micro hydro turbine power in each season.

TABLE IV

COEFFICIENTS FOR CONVERTING THE ENERGY CARRIERS

\begin{tabular}{ccc}
\hline From & To & Coefficient \\
\hline Electricity $(\mathrm{kWh})$ & Hydrogen $(\mathrm{kg})$ & 45 \\
$\mathrm{CO}_{2}(\mathrm{~kg})$ & Methane $(\mathrm{kg})$ & 2.7 \\
Hydrogen $(\mathrm{kg})$ & Methane $(\mathrm{kg})$ & 0.5 \\
Methane $(\mathrm{kg})$ & Electricity $(\mathrm{kWh})$ & 14.65 \\
\hline
\end{tabular}

\section{NUMERICAL RESULTS AND DISCUSSIONS}

The multi-carrier energy system is successfully simulated on the introduced net zero energy building. 
The model minimizes the environmental pollutions by capturing the released $\mathrm{CO}_{2}$ of the building. The designed system captures $33451.330 \mathrm{~kg}$ of $\mathrm{CO}_{2}$ per year. The captured $\mathrm{CO}_{2}$ in different seasons and hours is shown by Fig. 8. The captured $\mathrm{CO}_{2}$ is used to produce methane gas for thermal units. The captured $\mathrm{CO}_{2}$ is therefore increased during winter when the thermal loads are bigger. Minimum $\mathrm{CO}_{2}$ is captured during summer when the thermal load demand is on the minimum level.

In the electrical sector, the wind-solar-hydro-CHP systems produce the electricity to supply the electrical demand, electric heating, and water electrolyzer. The PHS is a supplementary device to level the intermittency of these resources. The discharged power from PHS is depicted in Fig. 9 and the charged power to PHS is represented by Fig. 10. The results demonstrate that the PHS does not show much operation. It is discharged at hours 18 to 22 and charged at hours 2 and 4. Such operation demonstrates that the intermittency of the input energies is restrained by their operation patterns and the PHS is not needed to operate very much. This point is justified by evaluating the energy profile of the input energy carriers. The wind, solar and hydro are the input energy carriers and as it was already shown, they have complementary energy profiles under various seasons and hours. It means when one energy profile is reduced the other ones are increased and such complementary profiles flatten the energy intermittency and the PHS operation is kept on the minimum level.

The stored energy inside the PHS system is depicted in Fig. 11. The most operation is seen in the summer when the electrical load is maximum and the system needs PHS to supply the peak demand at hours 18 to 20 . The energy arbitrage is done from initial hours of the day to the peak demand hours.

The CHP unit produces both the electricity and thermal energy. Fig. 12 shows the produced electricity by CHP unit. The most electricity is produced in the summer when the electrical energy demand is high. The minimum operation is in the winter when the electrical load is not considerable but the thermal load demand is maximum. Consequently, the CHP devotes its capacity to produce thermal energy and the electrical energy is kept on the lower levels.

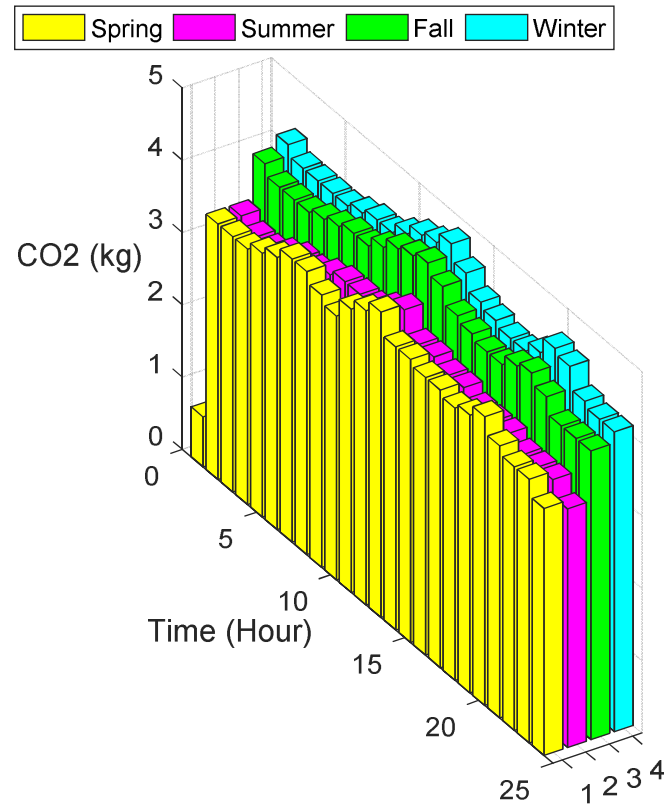

Fig. 8: Captured $\mathrm{CO}_{2}$ in different seasons.
Table V presents the produced thermal energy by CHP and boiler. The CHP unit produces maximum thermal energy in the winter to supply the thermal demand. In the summer, the capacity of CHP is devoted to electrical energy production and thermal energy is mostly supplied by thermal boiler. The thermal boiler works on the maximum capacity at most hours because it consumes the methane and the methane is made of $\mathrm{CO}_{2}$. Consequently, consuming more methane needs to capture more $\mathrm{CO}_{2}$ resulting in further $\mathrm{CO}_{2}$ reduction.

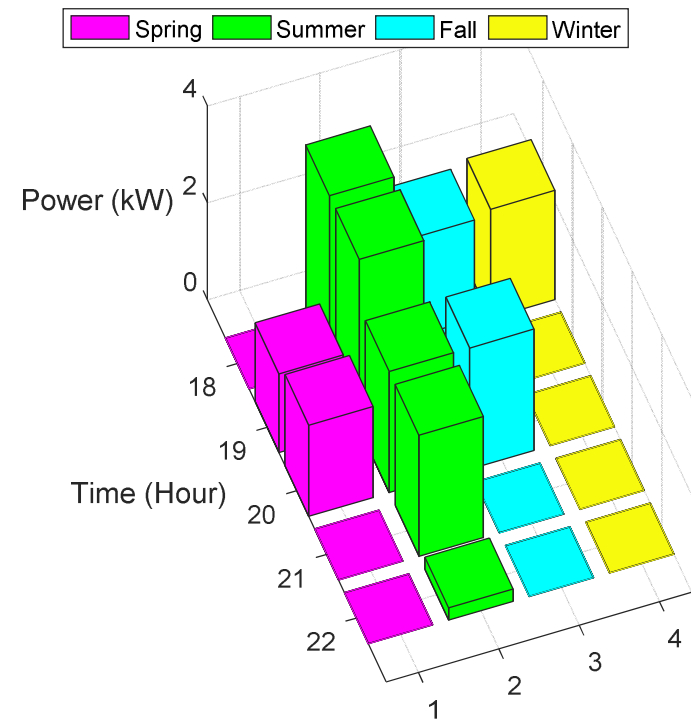

Fig. 9: Discharged power from PHS

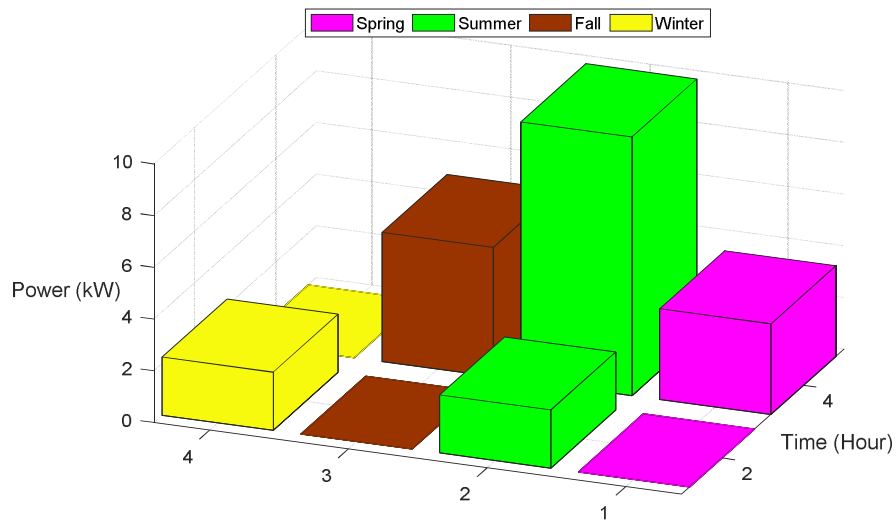

Fig. 10: Charged power to PHS.

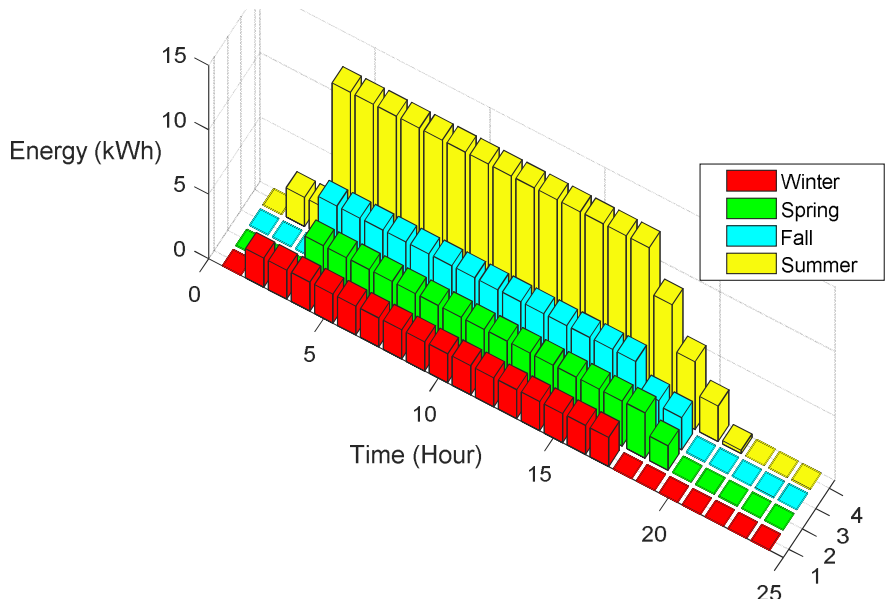

Fig. 11: Energy arbitrage by pumped hydro storage. 


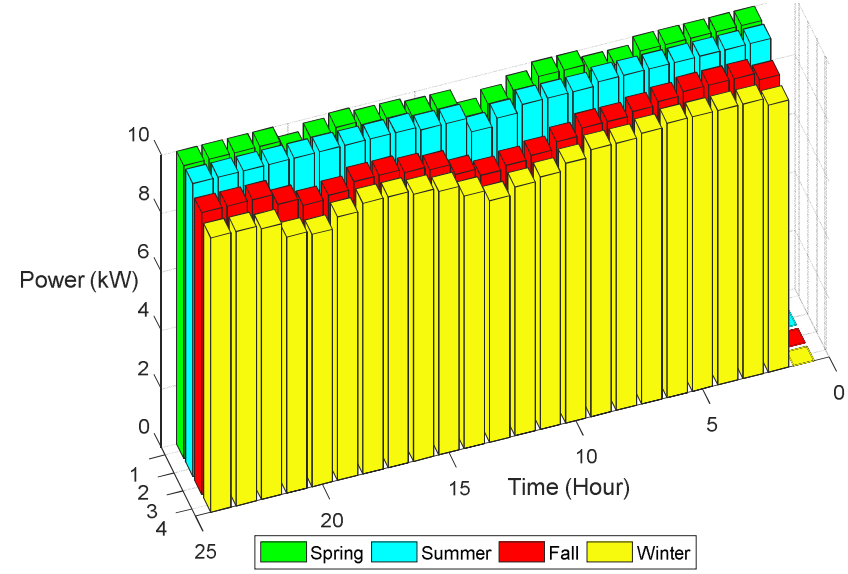

Fig. 12: Produced electricity by CHP.

Table VI shows the operating pattern of electric heating. The electric heating is not extensively operated by the plan because it does not consume the methane and it is fed by electrical energy. In the beginning hour of the plan, the plan uses this device because the initial energy of the hydrogen tank is zero and the CHP cannot operate to supply the thermal load. For the next hours, the CHP begins to operate and the electric heating operation is not needed anymore and it is therefore switched off.

The medium energy carriers between the electrical and thermal sections are the hydrogen and methane gases. Table VII presents the produced methane and hydrogen. The model converts most of the produced hydrogen to methane in order to feed the thermal boiler and CHP. The produced hydrogen and Methane are increased in the winter because of more demand for thermal energy.

TABLE V

PRODUCED THERMAL ENERGY BY CHP AND BOILER

\begin{tabular}{ccccccccc}
\hline \multicolumn{8}{c}{ CHP thermal output $(\mathrm{kW})$} & \multicolumn{5}{c}{ Thermal boiler (kW) } \\
Hour & Spring & Summer & Fall & Winter & Spring & Summer & Fall & Winter \\
\hline 1 & 0 & 0 & 0 & 0 & 3 & 2.949 & 2.75 & 3 \\
2 & 0 & 0 & 2.5 & 3.5 & 2 & 2 & 3 & 3 \\
3 & 0 & 0 & 1.5 & 2.5 & 2 & 1.5 & 3 & 3 \\
4 & 0 & 0 & 1.5 & 2.5 & 2 & 1.5 & 3 & 3 \\
5 & 0 & 0 & 1.5 & 2.5 & 2.5 & 2 & 3 & 3 \\
6 & 0 & 0 & 2 & 2.5 & 3 & 2.5 & 3 & 3 \\
7 & 1 & 0 & 2.5 & 3 & 3 & 2.5 & 3 & 3 \\
8 & 1 & 0 & 3 & 3.5 & 3 & 3 & 3 & 3 \\
9 & 0 & 0.5 & 3 & 3.5 & 3 & 3 & 3 & 3 \\
10 & 0 & 0.5 & 4 & 4.5 & 2.5 & 3 & 3 & 3 \\
11 & 1 & 0.5 & 5 & 5.5 & 3 & 3 & 3 & 3 \\
12 & 2 & 1.5 & 5.5 & 6 & 3 & 3 & 3 & 3 \\
13 & 3 & 2.5 & 6 & 7 & 3 & 3 & 3 & 3 \\
14 & 1 & 0.5 & 5 & 5.5 & 3 & 3 & 3 & 3 \\
15 & 1 & 0.5 & 3.5 & 4 & 3 & 3 & 3 & 3 \\
16 & 0.5 & 0 & 3 & 3.5 & 3 & 3 & 3 & 3 \\
17 & 0.5 & 0 & 2.5 & 3 & 3 & 3 & 3 & 3 \\
18 & 0 & 0 & 2.5 & 3 & 3 & 2.5 & 3 & 3 \\
19 & 0.5 & 0 & 3.5 & 4 & 3 & 2.5 & 3 & 3 \\
20 & 1.5 & 0 & 4 & 5.5 & 3 & 2.5 & 3 & 3 \\
21 & 0 & 0 & 3 & 5 & 3 & 2 & 3 & 3 \\
22 & 0 & 0 & 1.5 & 3 & 2.5 & 2 & 3 & 3 \\
23 & 0 & 0 & 1.5 & 2.5 & 2.5 & 2 & 3 & 3 \\
24 & 0 & 0 & 1.5 & 2.5 & 1.5 & 1 & 3 & 3 \\
\hline
\end{tabular}

TABLE VI

PRODUCED THERMAL ENERGY BY ELECTRIC HEATING PER KW

\begin{tabular}{ccccc}
\hline Hour & Spring & Summer & Fall & Winter \\
\hline 1 & 0.500 & 0.051 & 2.743 & 3.500 \\
2 to 24 & 0 & 0 & 0 & 0 \\
\hline
\end{tabular}

TABLE VII

PRODUCED METHANE AND HYDROGEN PER KG

\begin{tabular}{ccccccccc}
\hline & \multicolumn{3}{c}{ Produced Methane $(\mathrm{kg})$} & \multicolumn{5}{c}{ Produced Hydrogen $(\mathrm{kg})$} \\
Hour & Spring & Summer & Fall & Winter & Spring & Summer & Fall & Winter \\
\hline 1 & 0.256 & 0.252 & 0.235 & 0.256 & 0.148 & 0.126 & 0.118 & 0.158 \\
2 & 1.308 & 1.308 & 1.536 & 1.593 & 0.634 & 0.654 & 0.768 & 0.766 \\
3 & 1.308 & 1.266 & 1.479 & 1.536 & 0.654 & 0.633 & 0.739 & 0.768 \\
4 & 1.308 & 1.266 & 1.479 & 1.536 & 0.654 & 0.633 & 0.739 & 0.768 \\
5 & 1.351 & 1.308 & 1.479 & 1.536 & 0.675 & 0.654 & 0.739 & 0.768 \\
6 & 1.394 & 1.351 & 1.507 & 1.536 & 0.697 & 0.675 & 0.754 & 0.768 \\
7 & 1.451 & 1.351 & 1.536 & 1.564 & 0.725 & 0.675 & 0.768 & 0.782 \\
8 & 1.451 & 1.394 & 1.564 & 1.593 & 0.725 & 0.697 & 0.782 & 0.796 \\
9 & 1.394 & 1.422 & 1.564 & 1.593 & 0.697 & 0.711 & 0.782 & 0.796 \\
10 & 1.351 & 1.422 & 1.621 & 1.65 & 0.675 & 0.711 & 0.811 & 0.825 \\
11 & 1.451 & 1.422 & 1.678 & 1.706 & 0.725 & 0.711 & 0.839 & 0.853 \\
12 & 1.507 & 1.479 & 1.706 & 1.735 & 0.754 & 0.739 & 0.853 & 0.867 \\
13 & 1.564 & 1.536 & 1.735 & 1.792 & 0.782 & 0.768 & 0.867 & 0.896 \\
14 & 1.451 & 1.422 & 1.678 & 1.706 & 0.725 & 0.711 & 0.839 & 0.853 \\
15 & 1.451 & 1.422 & 1.593 & 1.621 & 0.725 & 0.711 & 0.796 & 0.811 \\
16 & 1.422 & 1.394 & 1.564 & 1.593 & 0.711 & 0.697 & 0.782 & 0.796 \\
17 & 1.422 & 1.394 & 1.536 & 1.564 & 0.711 & 0.697 & 0.768 & 0.782 \\
18 & 1.394 & 1.351 & 1.536 & 1.564 & 0.697 & 0.675 & 0.768 & 0.782 \\
19 & 1.422 & 1.351 & 1.593 & 1.621 & 0.711 & 0.675 & 0.796 & 0.811 \\
20 & 1.479 & 1.351 & 1.621 & 1.706 & 0.739 & 0.675 & 0.811 & 0.853 \\
21 & 1.394 & 1.308 & 1.564 & 1.678 & 0.697 & 0.654 & 0.782 & 0.839 \\
22 & 1.351 & 1.308 & 1.479 & 1.564 & 0.675 & 0.654 & 0.739 & 0.782 \\
23 & 1.351 & 1.308 & 1.479 & 1.536 & 0.675 & 0.654 & 0.739 & 0.768 \\
24 & 1.266 & 1.223 & 1.479 & 1.536 & 0.633 & 0.611 & 0.739 & 0.768 \\
\hline
\end{tabular}

\section{A. Energy hub resilience}

In order to keep the load services available following events, the initial energy of PHS and hydrogen tank are optimized. The initial energy of PHS is optimized on zero and the initial hydrogen inside the tank is optimized on $1 \mathrm{~kg}$. The purpose is to minimize the load shedding following events.

Table VIII presents the thermal energy productionconsumption following disruptions. Under the normal operating condition when no outage is occurred, the CHP and thermal boiler are operated to supply the thermal loads. The electric heating is not used because it does not make any impact on $\mathrm{CO}_{2}$ reduction $\left(\mathrm{CO}_{2}\right.$ reduction is the objective of the plan). Once CHP or thermal boiler are not functioning, the electric heating is operated to supply the thermal loads. The thermal load shedding is zero in all cases and the system is resilient under the failures. The electrical load is supplied by renewable energy carriers, CHP, and PHS systems.

The system is able to supply the electrical load following various events as indicated by Table IX.

\section{B. Adequacy and scalability}

The ability of system following load growth is addressed in Table X. While the initial hydrogen inside the hydrogen tank is zero, the system is able to supply the electrical loads $26 \%$ beyond the normal level and the thermal loads $10 \%$ more than the normal load level. In contrast, when there is one $\mathrm{kg}$ of hydrogen inside the hydrogen tank, the system ability is expressively increased and it is able to supply the thermal loads until $50 \%$ more than the normal operating condition.

TABLE VIII

THERMAL ENERGY PRODUCTION AND CONSUMPTION FOLLOWING EVENT

\begin{tabular}{ccccc}
\hline & CHP & $\begin{array}{c}\text { Thermal } \\
\text { boiler }\end{array}$ & $\begin{array}{c}\text { Electric } \\
\text { heating }\end{array}$ & $\begin{array}{c}\text { Captured } \\
\mathrm{CO}_{2}(\mathrm{~kg})\end{array}$ \\
\hline No outage & $\begin{array}{c}\text { Moderate } \\
\text { operation }\end{array}$ & $\begin{array}{c}\text { Maximum } \\
\text { operation }\end{array}$ & - & 34653 \\
\hline $\begin{array}{c}\text { Thermal } \\
\text { boiler } \\
\text { outage }\end{array}$ & $\begin{array}{c}\text { Maximum } \\
\text { operation }\end{array}$ & - & $\begin{array}{l}\text { Moderate } \\
\text { operation }\end{array}$ & 32711 \\
\hline $\begin{array}{c}\text { Electric } \\
\text { heating } \\
\text { outage }\end{array}$ & $\begin{array}{c}\text { Moderate } \\
\text { operation }\end{array}$ & $\begin{array}{c}\text { Maximum } \\
\text { operation }\end{array}$ & - & 34653 \\
\hline $\begin{array}{c}\text { CHP } \\
\text { Thermal } \\
\text { power } \\
\text { outage }\end{array}$ & - & Maximum & Moderate & 32116 \\
operation & operation & \\
\hline
\end{tabular}


TABLE IX

ELECTRICAL ENERGY PRODUCTION AND CONSUMPTION FOLLOWING EVENTS

\begin{tabular}{cccc}
\hline & CHP & PHS & $\begin{array}{c}\text { Captured } \\
\mathrm{CO}_{2}(\mathrm{~kg})\end{array}$ \\
\hline No outage & Maximum operation & $\begin{array}{c}\text { Moderate } \\
\text { operation }\end{array}$ & 34653 \\
$\begin{array}{c}\text { Solar power } \\
\text { outage } \\
\text { Wind power } \\
\text { outage }\end{array}$ & Maximum operation & $\begin{array}{c}\text { Maximum } \\
\text { operation }\end{array}$ & 34653 \\
\hline
\end{tabular}

TABLE X

THE SYSTEM ABILITY TO DEAL WITH LOAD GROWTH

\begin{tabular}{ccc}
\hline & Initial hydrogen inside the hydrogen tank \\
& 0 & 1 \\
\hline $\begin{array}{c}\text { Maximum possible increment } \\
\text { of electrical load (\%) }\end{array}$ & 26 & 26 \\
$\begin{array}{c}\text { Maximum possible increment } \\
\text { of thermal load (\%) }\end{array}$ & 10 & 50 \\
\hline
\end{tabular}

\section{Model without CHP operation}

The multi-carrier energy hub without CHP needs a larger PHS system to handle the energy issues. The simulations demonstrate that the system without CHP needs one PHS comprising $90 \mathrm{kWh}$ capacity, $20 \mathrm{~kW}$ power and $5 \mathrm{kWh}$ initial energy. The operation of such large-scale PHS is depicted in Fig. 13. The PHS stores energy up to $90 \mathrm{kWh}$ at summer and the energy arbitrage is done from the off-peak hours to on-peak demand periods. The operation is different from one season to another season because the electrical load follows different seasonal patterns.

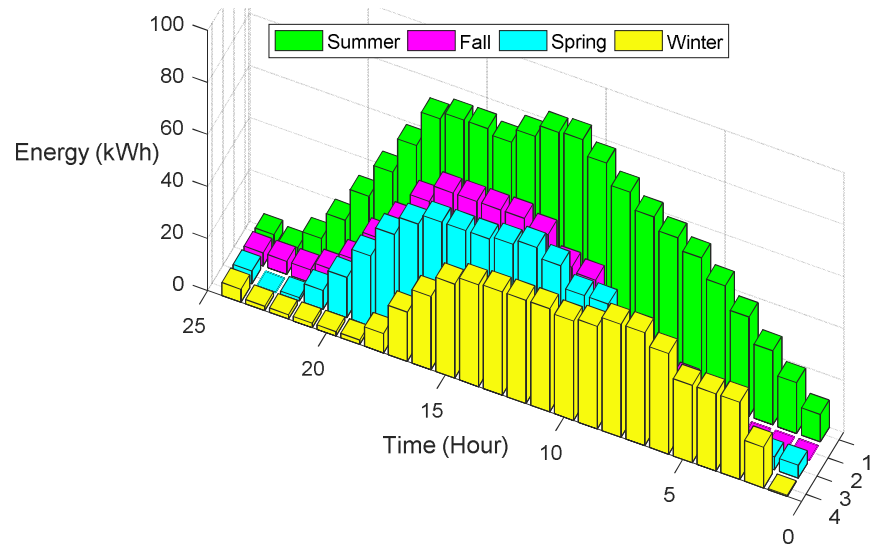

Fig. 13: PHS operation without CHP unit.

\section{Comparison study}

The proposed energy optimization strategy includes all energy resources at the same time. The other reported strategies in literature usually do not consider all resources simultaneously. There are various strategies excluding one or two of the given resources. The proposed strategy is compared with the other reported strategies in literature as listed in Table XI. Every strategy is modeled as the proposed strategy excluding one of the resources. The results verify that the given model is the most comprehensive model that can efficiently deals with outages and events. The feasible operation under N-1 contingencies is achieved. Additionally, the achievable electrical and thermal load growth in the proposed model is significantly more than the other systems.
TABLE XI

COMPARISON OF VARIOUS STRATEGIES

\begin{tabular}{clccc}
\hline Strategy & $\begin{array}{c}\text { Operation in } \\
\text { normal } \\
\text { condition }\end{array}$ & $\begin{array}{c}\text { Operation under } \\
\text { N-1 contingency }\end{array}$ & $\begin{array}{c}\text { Infeasible } \\
\text { part }\end{array}$ & $\begin{array}{c}\text { Maximum load } \\
\text { growth (\%) }\end{array}$ \\
\hline $\begin{array}{c}\text { Proposed model } \\
\text { (including all } \\
\text { resources) }\end{array}$ & Feasible & Feasible & - & $\begin{array}{c}\text { Thermal }=50 \\
\text { Electrical }=26\end{array}$ \\
\hline $\begin{array}{c}\text { Model without } \\
\text { thermal boiler }\end{array}$ & Feasible & Infeasible & $\begin{array}{c}\text { Thermal load } \\
\text { balance }\end{array}$ & $\begin{array}{c}\text { Thermal }=20 \\
\text { Electrical }=26\end{array}$ \\
\hline $\begin{array}{c}\text { Model without } \\
\text { electric heating }\end{array}$ & Feasible & Infeasible & $\begin{array}{c}\text { Thermal load } \\
\text { balance }\end{array}$ & $\begin{array}{c}\text { Thermal }=10 \\
\text { Electrical }=26\end{array}$ \\
\hline $\begin{array}{c}\text { Model without } \\
\text { CHP }\end{array}$ & Feasible & Infeasible & $\begin{array}{c}\text { Thermal load } \\
\text { balance }\end{array}$ & $\begin{array}{c}\text { Thermal }=5 \\
\text { Electrical }=15\end{array}$ \\
\hline $\begin{array}{c}\text { Model without } \\
\text { solar system }\end{array}$ & Feasible & Infeasible & $\begin{array}{c}\text { Electrical } \\
\text { load balance }\end{array}$ & $\begin{array}{c}\text { Thermal }=50 \\
\text { Electrical }=11\end{array}$ \\
\hline $\begin{array}{c}\text { Model without } \\
\text { wind system }\end{array}$ & Feasible & Infeasible & $\begin{array}{c}\text { Electrical } \\
\text { load balance }\end{array}$ & $\begin{array}{c}\text { Thermal }=50 \\
\text { Electrical }=4\end{array}$ \\
\hline $\begin{array}{c}\text { Model without } \\
\text { PHS }\end{array}$ & Feasible & Infeasible & $\begin{array}{c}\text { Electrical } \\
\text { load balance }\end{array}$ & $\begin{array}{c}\text { Thermal }=50 \\
\text { Electrical }=10\end{array}$ \\
\hline
\end{tabular}

\section{E. Sensitivity analysis}

The sensitivity analysis on some key parameters is listed in Table XII. It is seen that the thermal load makes impact on the captured $\mathrm{CO}_{2}$ because it is supplied by $\mathrm{CHP}$ and thermal generating systems which produce $\mathrm{CO}_{2}$. On the other hand, the electrical load is supplied by renewable resources and does not make impact on $\mathrm{CO}_{2}$. The initial hydrogen of system is also very important and the outputs are associated with this parameter. The system comprising more initial hydrogen operates more thermal units resulting in more $\mathrm{CO}_{2}$ production and capture. The $\mathrm{CHP}$ power has direct impact on $\mathrm{CO}_{2}$. The bigger CHP produces more $\mathrm{CO}_{2}$ resulting in more $\mathrm{CO}_{2}$ capture. The efficiency of the components is also important and makes impact on the model as demonstrated by the results.

\section{F. Model excluding hydro power and PHS}

The given model comprises micro hydro power and PHS system. The PHS system requires water storage at certain height to realize its potential and integrate it with the multi-carrier energy system. As well, the presence of hydro power in the vicinity of the many buildings and farms is not always practical and realizable. As a result, the model must have enough flexibility to operate without hydro power and PHS. In this regard, both the micro hydro power and PHS are removed from the model and it is simulated again. The results are presented in Table XIII. It is clear that the larger wind and solar systems are installed by the plan to compensate lack of hydro power. The larger wind-solar units can supply the loads while the hydro power and PHS are not present. As a result, the model can successfully be applied in the regions where the hydro power is not available and the PHS system is not feasible or practical. In such locations, the system only needs larger wind and solar energies.

TABLE XII

SENSITIVITY ANALYSIS ON THE PARAMETERS

\begin{tabular}{cc}
\hline Model & Change in captured $\mathrm{CO}_{2}(\%)$ \\
\hline Nominal operating condition & 0.0 \\
$15 \%$ increase in thermal load & +2.8 \\
$10 \%$ increase in electrical load & 0.0 \\
$100 \%$ decrease in initial hydrogen & -3.5 \\
$10 \%$ increase in CHP power & +5.8 \\
$10 \%$ decrease in CHP power & -5.8 \\
$20 \%$ increase in boiler efficiency & -3.2 \\
\hline
\end{tabular}


TABLE XIII

OPERATION EXCLUDING HYDRO AND PHS SYSTEMS

\begin{tabular}{ccc}
\hline Model & $\begin{array}{c}\text { Model including } \\
\text { all resources }\end{array}$ & $\begin{array}{c}\text { Model excluding } \\
\text { hydro power and } \\
\text { PHS }\end{array}$ \\
\hline Wind power $(\mathrm{kW})$ & 10 & 40 \\
\hline Solar power $(\mathrm{kW})$ & 10 & 13 \\
\hline PHS power $(\mathrm{kW})$ & 10 & - \\
\hline PHS capacity $(\mathrm{kWh})$ & 50 & - \\
\hline Hydro power $(\mathrm{kW})$ & 10 & 34653 \\
\hline Captured CO2 $(\mathrm{kg})$ & 34653 & Thermal $=50$ \\
Maximum load growth $(\%)$ & Thermal=50 & Electrical $=26$ \\
\hline
\end{tabular}

\section{MAIN ACHIEVEMENTS}

The proposed model utilized multiple energy resources including hydro, gas, sun, wind, Methane, and hydrogen at the same time. The cogeneration of these resources was optimized to supply both the thermal and electrical loads simultaneously. The combination of hydrogen-CHP-Methane made an interface between electrical and thermal energies. The supplementary devices like energy storage also optimized and operated to handle the intermittency of the input energies. The results demonstrated that combination of multiple resources and capacities provides better results in terms of resilience and pollution. The released $\mathrm{CO} 2$ of the building is minimized and the energy resilience is maximized. The PHS not only handles the intermittency of input energies but also helps the system to deal with on-peak load demand. As a result, application of multiple energy resources together with energy storage system is more efficient. The energy storage unit helps the system to utilize maximum functionality of the energy resources. The CHP is also very important in such multi-carrier energy system because it supplies on-peak electrical demand in summer and on-peak thermal demand in winter. As a result, such integrated electricity-gas system needs CHP unit in order to have maximum efficiency and functionality. In order to have the maximum energy resiliency, both the electrical and thermal loads must be supported by parallel paths. The thermal loads may be feed by electric heating and boiler and the electrical loads may be supplied by CHP as the substitute paths. Application of multiple energy and capacity resources increases the system adequacy and scalability. The system can easily cope with unpredicted load growth. The proposed energy hub shows feasible operation under N-1 contingencies.

\section{CONCLUSIONS}

The developed model for multi-carrier energy system in net zero energy buildings was successfully simulated and studied in this paper. The released $\mathrm{CO}_{2}$ of the building was minimized and about $33451 \mathrm{~kg}$ of $\mathrm{CO}_{2}$ is annually collected by the system. The $\mathrm{CO}_{2}$ is recycled to produce methane and supplying the thermal loads. The system collects more $\mathrm{CO}_{2}$ when the thermal load demand is higher, especially in the winter. The cogeneration of wind-solar-hydro-CHP-PHS was optimized to supply the electrical energy demands. Under normal operating condition the PHS is not operated often because the input energies have complementary energy profiles and their intermittency is handled by their balancing operating patterns. Thus, the PHS is not required to handle the renewable energy intermittency. The CHP operation was also in consistent with the load demands where it produced more electrical energy in the summer and more thermal energy in the winter. Most of the produced hydrogen was directly converted to methane for feeding the thermal devices. It was demonstrated that when the initial energy of hydrogen tank is one $\mathrm{kg}$, both the thermal and electrical loads are completely supplied following various failures of the components and the load shedding is zero. The adequacy and scalability of the system as also experienced following load growth. The system could successfully supply $26 \%$ increment in the electrical loads and $110 \%$ increment in the thermal loads. The results verify that the system without $\mathrm{CHP}$ needs a very large PHS with $90 \mathrm{kWh}$ capacity, $20 \mathrm{~kW}$ power and $5 \mathrm{kWh}$ initial energy.

\section{REFERENCES}

[1] S. Deng, R. Z. Wang, and Y. J. Dai. (2014, Jul.). How to Evaluate Performance of Net Zero Energy Building - a Literature Research. Energy. 71 pp. 1-16

[2] P. Hernandez, and P. Kenny. (2010, Jun.). From Net Energy to Zero Energy Buildings: Defining Life Cycle Zero Energy Buildings (Lc-Zeb). Energy and Buildings. 42 (6), pp. 815-821

[3] D. Kim, H. Cho, J. Koh, and P. Im. (2020, Feb.). Net-Zero Energy Building Design and Life-Cycle Cost Analysis with Air-Source Variable Refrigerant Flow and Distributed Photovoltaic Systems. Renewable and Sustainable Energy Reviews. 118 pp. 109508

[4] B. Celik, S. Suryanarayanan, R. Roche, and T. M. Hansen. (2020, Jan.). Quantifying the Impact of Solar Photovoltaic and Energy Storage Assets on the Performance of a Residential Energy Aggregator. IEEE Transactions on Sustainable Energy. 11 (1), pp. 405-414

[5] X. Wu, X. Hu, X. Yin, and S. J. Moura. (2018, Sept.). Stochastic Optimal Energy Management of Smart Home with Pev Energy Storage. IEEE Transactions on Smart Grid. 9 (3), pp. 2065-2075

[6] Y. Sun, R. Ma, J. Chen, and T. Xu. (2020, Feb.). Heuristic Optimization for Grid-Interactive Net-Zero Energy Building Design through the Glowworm Swarm Algorithm. Energy and Buildings. 208 pp. 109644

[7] H. Mehrjerdi, A. Iqbal, E. Rakhshani, and J. R. Torres. (2019, Dec.). DailySeasonal Operation in Net-Zero Energy Building Powered by Hybrid Renewable Energies and Hydrogen Storage Systems. Energy Conversion and Management. 201 pp. 112156

[8] V. Sharma, M. H. Haque, and S. M. Aziz. (2019, Oct.). Energy Cost Minimization for Net Zero Energy Homes through Optimal Sizing of Battery Storage System. Renewable Energy. 141 pp. 278-286

[9] R. Hemmati, H. Mehrjerdi, and M. Bornapour. (2020, Jul.). Hybrid Hydrogen-Battery Storage to Smooth Solar Energy Volatility and Energy Arbitrage Considering Uncertain Electrical-Thermal Loads. Renewable Energy. pp.

[10]Y. Zhou, and S. Cao. (2020, Mar.). Quantification of Energy Flexibility of Residential Net-Zero-Energy Buildings Involved with Dynamic Operations of Hybrid Energy Storages and Diversified Energy Conversion Strategies. Sustainable Energy, Grids and Networks. 21 pp. 100304

[11]M. Robati, D. Daly, and G. Kokogiannakis. (2019, Jul.). A Method of Uncertainty Analysis for Whole-Life Embodied Carbon Emissions (Co2-E) of Building Materials of a Net-Zero Energy Building in Australia. Journal of Cleaner Production. 225 pp. 541-553

[12]R. Hemmati. (2017, Aug.). Technical and Economic Analysis of Home Energy Management System Incorporating Small-Scale Wind Turbine and Battery Energy Storage System. Journal of Cleaner Production. 159 pp. 106-118

[13] O. Sotehi, A. Chaker, and C. Maalouf. (2016, May). Hybrid Pv/T Water Solar Collector for Net Zero Energy Building and Fresh Water Production: A Theoretical Approach. Desalination. 385 pp. 1-11

[14]G. Kayo, A. Hasan, and K. Siren. (2014, Oct.). Energy Sharing and Matching in Different Combinations of Buildings, Chp Capacities and Operation Strategy. Energy and Buildings. 82 pp. 685-695

[15]H. Mehrjerdi. (2019, May). Off-Grid Solar Powered Charging Station for Electric and Hydrogen Vehicles Including Fuel Cell and Hydrogen Storage. International Journal of Hydrogen Energy. 44 (23), pp. 11574-11583 
[16]H. Mehrjerdi, and R. Hemmati. (2020, Dec.). Coordination of Vehicle-toHome and Renewable Capacity Resources for Energy Management in Resilience and Self-Healing Building. Renew. Energy. 146 pp. 568-579

[17] Y. Cao, W. Wei, J. Wang, S. Mei, M. Shafie-khah, and J. P. S. Catalão. (2020, Jan.). Capacity Planning of Energy Hub in Multi-Carrier Energy Networks: A Data-Driven Robust Stochastic Programming Approach. IEEE Transactions on Sustainable Energy. 11 (1), pp. 3-14

[18]H. Chen, M. Liu, Y. Liu, S. Lin, and Z. Yang. (2020, Apr.). Partial Surrogate Cuts Method for Network-Constrained Optimal Scheduling of MultiCarrier Energy Systems with Demand Response. Energy. 196 pp. 117119

[19]T. Liu, D. Zhang, S. Wang, and T. Wu. (2019, Feb.). Standardized Modelling and Economic Optimization of Multi-Carrier Energy Systems Considering Energy Storage and Demand Response. Energy Conversion and Management. 182 pp. 126-142

[20]H. Mehrjerdi, M. Saad, and S. Lefebvre. (2020, Sept.). EfficiencyResilience Nexus in Building Energy Management under Disruptions and Events. IEEE System Journal. 1 (1), pp. 1-10

[21] R. Hemmati, H. Mehrjerdi, M. Shafie-khah, P. Siano, and J. P. S. Catalao. (2020, Sept.). Managing Multitype Capacity Resources for Frequency Regulation in Unit Commitment Integrated with Large Wind Ramping. IEEE Transactions on Sustainable Energy. 1 (1), pp. 1-1

[22]T. Lan, and K. Strunz. (2019, Dec.). Modeling of the Enthalpy Transfer Using Electric Circuit Equivalents: Theory and Application to Transients of Multi-Carrier Energy Systems. IEEE Transactions on Energy Conversion. 34 (4), pp. 1720-1730

[23]H. R. Massrur, T. Niknam, and M. Fotuhi-Firuzabad. (2018, Nov.). Investigation of Carrier Demand Response Uncertainty on Energy Flow of Renewable-Based Integrated Electricity-Gas-Heat Systems. IEEE Transactions on Industrial Informatics. 14 (11), pp. 5133-5142
[24]E. Haghi, M. Fowler, and K. Raahemifar. (2019, Apr.). Co-Benefit Analysis of Incentives for Energy Generation and Storage Systems; a MultiStakeholder Perspective. International Journal of Hydrogen Energy. 44 (19), pp. 9643-9671

[25] Y. Cheng, N. Zhang, Z. Lu, and C. Kang. (2019, Sept.). Planning Multiple Energy Systems toward Low-Carbon Society: A Decentralized Approach. IEEE Transactions on Smart Grid. 10 (5), pp. 4859-4869

[26]L. Ma, N. Liu, J. Zhang, W. Tushar, and C. Yuen. (2016, Oct.). Energy Management for Joint Operation of Chp and Pv Prosumers inside a GridConnected Microgrid: A Game Theoretic Approach. IEEE Transactions on Industrial Informatics. 12 (5), pp. 1930-1942

[27] N. Liu, L. He, X. Yu, and L. Ma. (2018, May). Multiparty Energy Management for Grid-Connected Microgrids with Heat- and ElectricityCoupled Demand Response. IEEE Transactions on Industrial Informatics. 14 (5), pp. 1887-1897

[28]Y. Dai, L. Chen, Y. Min, Q. Chen, K. Hu, J. Hao, Y. Zhang, and F. Xu. (2017, Jul.). Dispatch Model of Combined Heat and Power Plant Considering Heat Transfer Process. IEEE Transactions on Sustainable Energy. 8 (3), pp. 1225-1236

[29] J. Toubeau, Z. D. Grève, P. Goderniaux, F. Vallée, and K. Bruninx. (2020, Nov.). Chance-Constrained Scheduling of Underground Pumped Hydro Energy Storage in Presence of Model Uncertainties. IEEE Transactions on Sustainable Energy. 11 (3), pp. 1516-1527

[30]H. Mehrjerdi. (2019, Apr.). Optimal Correlation of Non-Renewable and Renewable Generating Systems for Producing Hydrogen and Methane by Power to Gas Process. International Journal of Hydrogen Energy. 44 (18), pp. $9210-9219$ 